em rede

\title{
Sobre muros de xisto, javalis e árvores: modos possíveis de habitar numa aldeia do interior de Portugal
}

\author{
On shist walls, wild boars and trees: possible ways of living in \\ a village in the interior of Portugal
}

\author{
Enviado em: 30/09/2020 \\ Aceito em: 05/01/20 \\ Ema Pires ${ }^{1}$ \\ Ricardo S. de Campos ${ }^{2}$
}

\section{Resumo}

Este texto discute modos possíveis de habitar o meio rural do interior de Portugal, com enfoque empírico numa freguesia rural onde foi realizada etnografia, com visitas pontuais, de modo extensivo, em 2004, 2016, 2018, 2019 e, de modo intensivo, em 2020. Localizada no distrito de Castelo Branco, concelho de Proença-a-Nova, a Mó é uma aldeia quase desabitada (4 residentes permanentes em 2019, 3 residentes em 2020). Argumentamos que, durante a emergência pandémica de 2020, habitar a aldeia em análise significa um aumento no valor social dado à natureza pela maioria dos residentes.

Palavras-chave: Espaço; Tempo; Ruralidade; Patrimónios; Portugal

\section{Abstract}

The present text discusses possible ways of inhabiting rural areas in the interior of Portugal, with an empirical focus in a rural parish where ethnography was carried out, with occasional visits, in an extensive way, in 2004, 2016, 2018, 2019 and, intensively, in 2020. Located in the district of Castelo Branco, municipality of Proença-a-Nova, Mó is an almost uninhabited village (4 permanent residents in 2019, 3 residents in 2020). We argue that, during the 2020 pandemic emergency, inhabiting the village under analysis means an increase in the social value given to nature by most residents.

Keywords: Space; Time; Rurality; Heritage; Portugal

1 - Antropóloga. Professora do Departamento de Sociologia da Universidade de Évora, Portugal. Investigadora Integrada no Instituto de História Contemporânea (IHC-UÉvora).

2 - Sociólogo. Professor da Faculdade de Ciências Sociais da Universidade de Goiás, Brasil. Pesquisador Colaborador no Centro CICSNova.UEvora, Portugal. 


\section{Introdução, ou reminiscências pessoais do "tempo da Mó"}

A Beira Baixa é uma região do interior localizada no centro-sul de Portugal ${ }^{3}$. Com características e singularidades muito específicas de zona de transição entre o norte e o sul. A região de Proença-a-Nova, onde o presente estudo foi realizado é caracterizada por uma extrema fragmentação fundiária e por topografia predominante de montanha, concentrando uma das maiores áreas de floresta de pinheiro bravo (Pinuspinaster) da Europa. Nas últimas décadas, a região tem sido marcada pela ocorrência de incêndios (espontâneos e provocados). Algumas das marcas da apropriação cultural deste território têm acompanhado a tendência mais geral do interior de Portugal, evidenciando-se o êxodo rural para áreas urbanas da região do país e do estrangeiro. O calendário anual das localidades tem sido marcado pelo retorno pontual e periódico destes migrantes durante as festividades comunitárias e as férias de verão. Acentua-se nesta microrregião, como marca histórica, a prática de uma agricultura de subsistência, particularmente de olival, numa região de fraca construção de mercados, em que o capitalismo chegou tardiamente.

Assumimos a premissa de que habitar é construir e manter vínculos com outros seres vivos mais ou menos distantes. Esta é uma coexistência que acontece com seres e objetos inanimados, embora também possam ser carregados (ou não) com memórias ou significados. O enfoque analítico é explorar os modos usados pelos residentes permanentes e ocasionais para gerir as transformações no ecossistema que os rodeia, em particular, na relação com o tempo, a floresta e os incêndios florestais.

Como sabemos, Portugal é um país de industrialização tardia, como sabemos. O interior de Portugal, a exemplo das aldeias do Concelho de Proença-Nova, de onde falamos, passou pelo processo de despovoamento sem nunca ter entrado propriamente no modelo urbano-industrial. Desde as grandes concentrações populacionais apinhadas em aldeias e vilas, vivendo à distancia dos grandes mercados. Também das conquistas sociais originárias do poder associativo dos sindicatos e de outras associações atreladas ao trabalho livre, ou assalariamento, as

3 - A região a que nos referimos neste texto como Beira Baixa, é identificada, na Nomenclatura das Unidades Territoriais para fins Estatísticos (NUTS), como abrangendo seis municípios: Castelo Branco, Idanha-a-Nova, Oleiros, Penamacor, Proença-a_Nova e Vila Velha de Rodão. 
populações do interior viveram e experimentaram uma temporalidade singular fazendo um elo entre a vida rural e de aldeia, organizada pelo trabalho agríicola e pelos limites colocados pela natureza, com o "retorno", marcado pela experiencia dos imigrantes.

Nas últimas décadas, o êxodo rural foi intensificado pela (in)certeza de incêndios ocasionais que têm devastado a região. Em 2003, a vila foi cercada pelo fogo e, apesar de as casas e os seres humanos terem sido poupados da destruição, tudo em volta de Mó foi transformado em cinzas, queimando árvores e matando os animais que viviam nas florestas de pinheiros que cercavam a aldeia.

Uma das poucas descrições escritas sobre este lugar, e isso ainda quando havia no lugar algumas dezenas de almas, dá a seguinte contextualização:

\begin{abstract}
"História: Mó é uma aldeia perdida nos confins do concelho, limitrofe dos concelhos de Oleiros e Castelo Branco. O lagar aqui construído em dimensões reduzidas corresponde à luta pela emancipação, dos pequenos proprietários, frente aos do Alvito da Beira". (LAGARES, 1982, p. 16).
\end{abstract}

Para pensarmos num "tempo da Mó", como tempo do interior rural de Portugal, que não incorra diretamente na dependência que o proprio conceito que tempo tem daquele de espaço, pensaremos num tempo da memória mais que um tempo do lugar. Significa, ler a experiencia da quarentena e o contacto com o lugar (a horta, a floresta, terras de agricultura, a aldeia, a internet, colaboração, ribeira, etc.) pela ótica das narrativas e da memória dos moradores ou antigo moradores, na reconstrução "desordenada" da (s) memória (s) vivida (s) (das narrativas) em relação com aquela que experimentamos em abril/maio de 2020. Assim, a memória da Mó, ou que se tem da Aldeia como lugar vivido no compartilhamento é o antidoto contra a sua extinção, considerando as "setenta e oito almas" que ali viviam em 1911 e os três moradores permanentes em 2020. O autor chave que utilizamos aqui para pensar o conceito e tempo e memória é o argentino Jorge Luis Borges, para quem a memória é o antidoto contra a morte. Assim destacamos a união temporal de um conjunto de memórias compartilhadas e vividas como recurso idealista contra a morte e ao mesmo tempo como recurso ou antidoto que minimize a relação interdependente entre tempo e espaço, qual conceito da fisica ou mesmo da metafisica. Também, Norbert Elias (1989) que estrutura seu pensamento a partir do conceito de tempo. Qual o sentido de viver o tempo da Mó? Que tempo é esse? 


\title{
O lugar
}

Um lugar pequeno e remoto? A aldeia de Mó pertence ao município de Proença-a-Nova e, mais especificamente, à União de Freguesias de Alvito da Beira e Sobreira Formosa, localizada a trinta quilómetros de Castelo Branco, capital do distrito. A história local de lugares como Mó e muitas outras periferias rurais do centro sul de Portugal tem sido amplamente sub-representada nas arenas acadêmicas. Na região em estudo, o campo permanece bastante invisível no cenário acadêmico. As únicas referências estão relacionadas a obras históricas de padres locais (CATHARINO, 1933), ou monografias regionais de etnógrafos locais não profissionais (VILHENA, 1995). Vilhena aponta em sua pesquisa a resiliência dos laços comunitários entre aldeias rurais da área de Proença. Nas palavras desta autora:

\begin{abstract}
"No concelho de Proença-a-Nova, apesar do progresso, o comunitarismo continua bem vivo, e de um alcance extraordinário. Eram comunitários os fornos, as eiras, o lagar, o alambique, o pulverizador, os moinhos, o almofariz, a balança de pesar os porcos, os rebanhos, as águas das regas, o esquife e a casa onde se guardava" (VILHENA, 1995: p. 52)
\end{abstract}

Particularmente, no caso de Mó, a existência de espaços, trabalhos ${ }^{4}$ e práticas comunitárias materializa-se hoje sobretudo na manutenção do forno comunitário (usado como lugar de reunião e confeção de alimentos) e na partilha das águas das regas. Antes da pandemia, era costume fazer refeições coletivas, na praça ao lado do forno comunitário da vila. A comensalidade comunitária foi interrompida pela Covid-19.

Como referido anteriormente, nas últimas décadas, o êxodo rural foi intensificado pela (in)certeza de incêndios ocasionais que devastaram a região. Em 2003, a aldeia foi cercada pelo fogo e, apesar de as casas e os seres humanos terem sido poupados da destruição, tudo ao redor de Mó se transformou em cinzas. As florestas de pinheiros ao redor da localidade foram queimadas junto com muitos dos animais que viviam nelas. É, portanto, a segunda vez no século XXI que a aldeia de Mó se torna (quase) completamente isolada do resto do país. Em agosto de 2003, o tempo ou a percepção do tempo foram subitamente congelados. Naquela época, o isolamento era significativo, porque o fogo queimou linhas telefônicas,

4 - Em perspetiva antropológica comparativa vejam-se, para outras regiões de Portugal, as análises de vários autores (cf. Dias,1953; O’Neill, 1984; Portela, 1986). 
postes de eletricidade e, além disso, também destruiu as esperanças das pessoas em relação ao futuro. Após o incêndio, e nos anos seguintes, a aldeia encolheu: várias pessoas migraram, outras morreram. Em 2020, dezassete anos depois, Mó é, mais uma vez, um lugar sitiado, forçada a se isolar, tentando se proteger de um tipo de desastre natural totalmente diferente. Desta vez, no entanto, a aldeia não encolheu, estendeu-se: quatro casas têm pessoas novamente. São pessoas que fugiram da cidade rumo as suas raízes encontrando um lugar seguro na floresta de pinheiros, para passar seu tempo durante o estado de emergência decretado em função da pandemia de coronavírus. Como referimos (PIRES, 2020; PIRES e CAMPOS, 2019), nos últimos meses, acessar a internet é um desafio diário, o que força os moradores de Mó a deixar suas casas para escalar a montanha vizinha. Para trabalhar ou simplesmente se comunicar. As pessoas sobem (a pé ou de carro) até o topo da Barreira, uma montanha localizada a noroeste do lugar. Todos os moradores coexistem nesse espaço de reuniões, onde intermitentemente nos encontramos, à distância, em diferentes dias da semana e em diferentes momentos do dia. Todos os moradores habitam esta montanha, agora transformada em uma varanda para falar ao telefone e viajar para o mundo virtual.

A Mó é distante do ponto de referência central, que neste caso pode ser Lisboa, ou a margem litorânea de Portugal, lugares em que o tempo da experiencia é marcado pela história do desenvolvimento do capitalismo. Por isso são definidos como ponto de referência. A distância mais que meramente geográfica (espacial) engendra o percurso da experiência cristalizada como locais de urbanidade, serviços, restaurantes, transportes, e tudo aquilo que marca o capitalismo, principalmente na sua fase industrial. Aqui onde estamos, no interior, a marca é de um "tempo distante", pois a memória, guardiã (razão) do tempo nos remete aos antepassados desta terra, de gente e mais gente penduradas por estas encostas de serra, e que daqui não "podiam" sair, e aqui construíam o tempo da sua experiência, experiencia de uma "Mó" girando lentamente e triturando grãos com o ritmo lento da ribeira - um curso d'água natural do que se dispunha, quando a base energética da pulsante capitalismo industrial já deixava de ser o vapor e já andava pelo petróleo. De muito em luta, saíram, suas experiências cristalizadas são reconhecidas como "um tempo que passou". Mas e agora que o território continua, e é reabitado por pessoas que estabelecem uma relação diferente com o território, para as quais é preciso construir outras experimentações? Olhando para a experiencia e a 
consciência dos nossos avós o tempo ganha o significado ancestral do enigma; mas olhando para as experiências cotidianas no território, abre-se um novo fluxo de vida, e, portanto, de potência transformadora, ainda mais "num tempo" em que o isolamento social passa a ser um bem, ou um valor, para os que pretendem privatizá-lo.

O conceito de "não lugar" para o antropólogo frances MarcAugé (1992) se refere ao lugar "de passagem", de transição que não constrói identidade, como caso exemplar de rodoviárias e aeroportos, em que se convive sem que com isso as pessoas construam narrativa. E como o trajeto ou travessia de um lugar para outro, as ruas, avenidas, transporte, etc, são "não lugares", que nos ligam sempre entre um lugar e outro lugar, este no caso dotado de estrutura narrativa, história e identidade. É a simbiose entre tecnologia, espaço e sociedade, segundo Augé (1992). São espaços fluídicos que permitem e facilitam a circulação a comunicação e o consumo de idéias e coisas, ou objetos. Este espaço de circulação e movimento de passagem, não seriam lugar por não possuirem significado, são locais de ligação apenas entre um lugar e outro lugar.

As narrativas nostálgicas sobre o lugar, fazem com que estes lugares se construam como "não lugar", já que tendem a transformar as pessoas em espectadores, ou no máximo em narradores, mas não atores. As narrativas congeladas de "um tempo" (passado), na conexão com "o tempo", presente, deixam vago "o real" tempo da Mó, e da ação do sujeito. Com o desaparecimento das pessoas e a facilitação de acesso com as novas tecnologias de comunicação as relações sociais são afetadas. A construção de identidade rompe com a dimensão do local, permitindo a formação de comunidades em longa distancia física. O que altera profundamente as relações sociais e redimensiona o entrecruzamento de" tempos diferentes". Atualmente na Mó há convivencia de tempos distintos entre alguns moradores que nunca saíram do local, outros que saíram e voltaram e outros ainda que chegaram agora, caso de moradores do norte da Europa, que compraram casas de habitação e transitam entre diferentes lugares (também "não lugares") e mundos.

\section{Xisto, árvores? Habitando o lugar}


Habitar estes lugares aparentemente 'remotos' envolve uma convivência que acontece com seres e objetos inanimados, embora também possam estar carregados de lembranças ou significados. Questionamos as relações entre pessoas, coisas e meio ambiente durante esses tempos de pandemia. Emaranhados em dados etnográficos, alguns exemplos empíricos são apresentados, provocando relações das pessoas com a natureza (muros de xisto, javalis e árvores). O caso das paredes do xisto segue esta visão: anteriormente construída para abrigar terraços utilizados para a agricultura - geralmente hortas, trepadeiras e principalmente oliveiras - hoje eles compõem o cenário de uma nova realidade que quase se reintegra com a natureza. Habitar também significa viver com animais selvagens ou domésticos, plantas e outras faunas e flora. Os animais domésticos, principalmente cães e gatos, desapareceram junto com os habitantes, mas o espaço local foi colonizado por outros animais. Alguns animais, como raposas e esquilos, e espécies vegetais foram reintroduzidos com sucesso, sua procriação facilitada por políticas públicas pagas após os incêndios. Outros seres vivos que se tornaram invasores naturais são javalis, que ocasionalmente invadem os arredores da Mó. Por fim, oliveiras antigas (e novas) permanecem abandonadas, lembrando aos humanos os desafios ambientais e as incertezas trazidas pelos tempos contemporâneos.

Em março de 2020, depois de uma rápida radicalização da recém decretada pela OMS - Organização Mundial da Saúde, pandemia do Covid 19, em meio a um clima de terror, desconfiança e medo, viemos para Mó. Há por aqui algumas dezenas de casas desabitadas, muitas a cair, outras funcionais, cujos proprietários não aparecem faz anos. Das 78 almas que por aqui vagavam em 1911, chegou-se ao número de 03 em 2020. Pois claramente a primeira pergunta simples e quase ingenua que fazemos é o que aconteceu neste "tempo" para que houvesse esta diminuição do número de habitantes? Por que a população humana diminuiu e a de javalis aumenta tanto?

Mó é o local de origem da família de um@ dos autor@s deste capítulo. Como a maioria da população deste lugar, são uma família de migrantes por várias gerações, morando entre Mó e outros lugares em Portugal e no mundo. Desde a década de 1960, gerações de membros da família visita(ra)m a Mó durante as férias e outras épocas festivas. Em março de 2020, logo após a pandemia de Covid-19 recentemente decretada pela OMS (Organização Mundial da Saúde) e em meio a um clima de terror, desconfiança e medo, a família decidiu ir morar na Mó. Até a 
pandemia, o retorno ali era visto como uma atividade de lazer de fim de semana. No entanto, desde que o período de emergência foi lançado em Portugal devido ao Covid-19, a casa da Mó tornou-se a principal morada da família. Nesse cenário empírico, um@d@s autores usou a auto etnografia (REED-DANAWAY, 1997) como ferramenta de descrição émica do contexto vivido. A próxima secção deste texto apresenta dados dessa experiência participante.

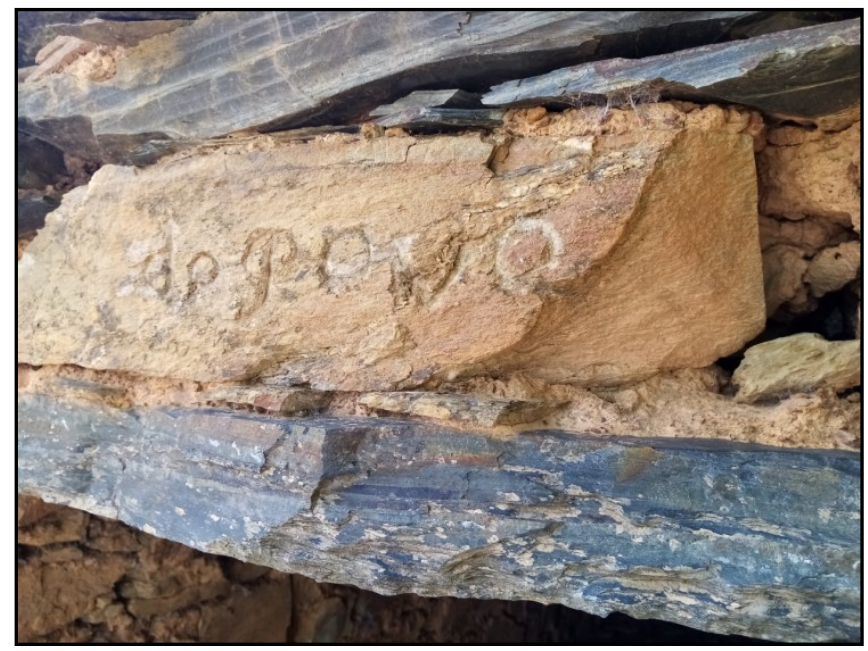

Figura 1: Muro de Xisto. Edifício Casa do Esquife, Mó. A inscrição "Do Povo" ("Do povo") data de 1936 (data indicativa) e lembra a prática de atividades sociais comunitárias e espaços comuns. Autor: Ema Pires (2020).

\section{Duas vinhetas etnográficas}

Nesta seção, exploramos o cotidiano de duas pessoas da Mó, entrelaçadas com as próprias experiências dos autores, com o objetivo de ilustrar nosso argumento.

\section{Primo Zé Maria}

Nascido em 1967, Zé Maria é atualmente um dos 3 residentes permanentes da Mó. Ele é solteiro e mora com o sobrinho. Sua família estava entre as mais pobres da localidade. Ao contrário de seu irmão mais velho e da maioria de seus tios ou primos, ele nunca migrou para Paris ou Lisboa. Sendo residente permanente da Mó, a vida toda, trabalhou como assalariado rural, noutras partes do país, mas nunca fora de Portugal. Antes da pandemia, ele costumava ganhar algum dinheiro fazendo 
biscates nas aldeias próximas. (Zé Maria é uma espécie de faz-tudo: trabalhador agrícola, assistente de pedreiro, corretor de imóveis informal, conhecedor de ervas e ventos). Durante a pandemia, a vida de Zé sofreu mudanças para melhor: ele tem mais vizinhos, mais companhia para conversar no largo principal no final da tarde. Embora a prática de ir às adegas da Mó para beber vinho e jeropiga tenha sido suspensa durante o estado de emergência, morar lá é, para Zé, estar menos sozinho. Zé não tem carro, viaja a pé e de ônibus para fora da Mó. O ônibus circula apenas às quintas-feiras e tem como destino final a vila de Proença-a-Nova. Em outros dias, quando ele precisa sair da aldeia, Zé caminha ou pega carona com alguém. Um de seus hobbies é caçar javalis nas proximidades da sua casa. A população de javalis e outros animais aumentou exponencialmente após os incêndios de 2003. Isso ocorreu, segundo ele, devido às políticas públicas que financiaram a introdução de espécies silvestres nas florestas queimadas e abandonadas, com o objetivo de aumentar a população de animais. No entanto, devido à falta de populações humanas e outros predadores que caçam javalis, eles se tornaram majoritários entre outras espécies, ameaçando plantas, árvores e outras culturas. Às vezes, javalis são vistos dentro das ruas da Mó durante a noite. Zé Maria usa armadilhas de metal para pegá-los.

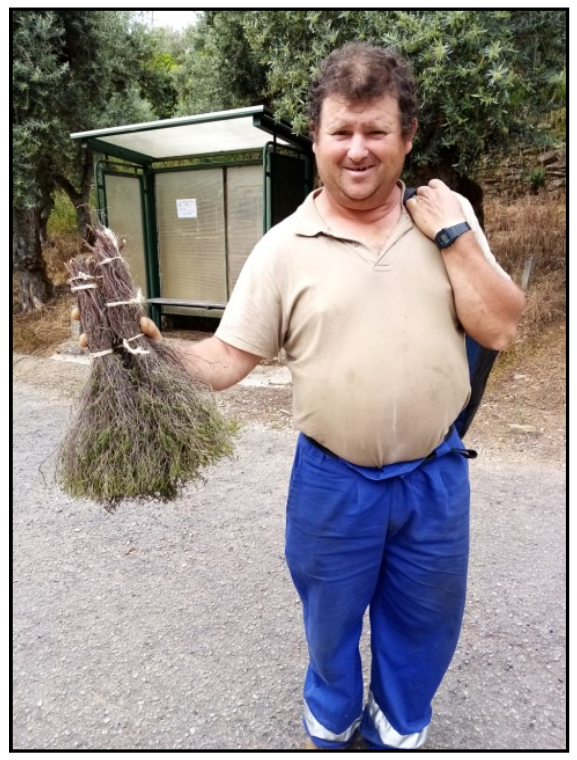

Figura 2: O residente permanente Zé Maria, regressando de uma de suas hortas, localizada no caminho ascendente para a montanha de Barreira, Mó. Regras e restrições públicas se aplicam à limpeza obrigatória dos campos com o objetivo de proteger a Mó dos incêndios. Autor: Ema Pires (2020). 


\section{Tia Leonor Rosa}

Nascida há 72 anos em Lisga (uma aldeia a 10 km de Mó), Leonor Rosa migrou em sua infância para Mó. Lá, ela trabalhou vários anos como empregada doméstica ("menina de servir em casa"), na casa de uma das famílias, e deixou a casa dos patrões para se casar com um rapaz da aldeia. Eles migraram para Lisboa, depois de se casarem.

Mãe de dois filhos (que vivem em Lisboa com suas famílias), ela passa a maior parte do ano viajando entre a Mó e Morelena (Sintra, perto de Lisboa), onde é residente permanente. Em Sintra, ela participa ativamente do coral da igreja local. A música é uma dimensão central da vida de Leonor: ela também é usuária frequente do youtube (para pesquisa musical) e também de redes sociais (Instagram e Whatsapp). No contexto atual da pandemia, não ter acesso diário à internet é uma das coisas de que mais sente falta. Na Mó, ela e o marido, ambos aposentados, são proprietários de três casas restauradas e cuidam de suas propriedades e terras. Ela cuida da paisagem de oliveiras e hortas. Além de regar suas próprias plantas, ela também cuida das árvores dos outros residentes não permanentes. No dia-a-dia, realiza regularmente trabalhos domésticos e agrícolas, e cuida da sua parente, a senhora mais velha da aldeia. Seu hobby principal é tocar órgão e cantar. Nas tardes de domingo Leonor não trabalha e por vezes organiza uma sessão de canto com outros moradores. Leonor Rosa e o marido estão morando na Mó desde o início de março de 2020. Eles vieram antes do início da pandemia, para participar do projeto de plantio de árvores ou reflorestamento na área circundante da aldeia, uma ação-piloto financiada pelo governo destinada à prevenção de incêndios. Este projeto recebeu cobertura da mídia pública (RÁDIO CONDESTÁVEL, 2020; RTP1, 2020) em serviços de radiodifusão regional e nacional. Devido ao Covid-19, as ações deste projeto programadas para a primavera de 2020 foram suspensas e adiadas para tempos futuros. 


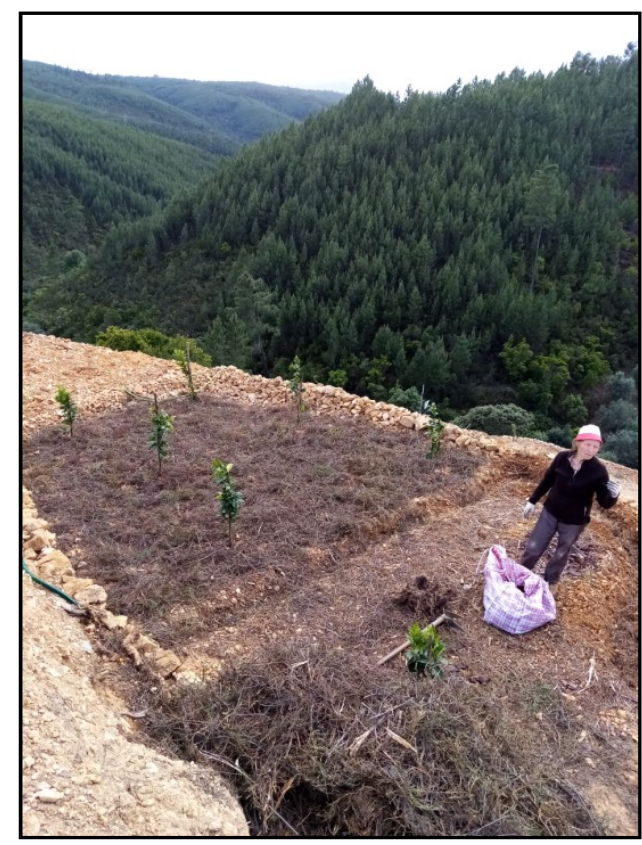

Figura 3: Terreno da tia Leonor Rosa, localizado na montanha de Barreira, Mó. Por causa da falta de abastecimento de água, Leonor usa galões de plástico para regar as plantas. Autor: Ema Pires (2020).

Argumentamos que, durante a pandemia, há um aumento no valor social dado à natureza pela maioria dos residentes. Valorizar a natureza (HARVEY, 1997) e habitar dentro da floresta, tem sido um recurso usado pelas pessoas para tentar ganhar o controle de suas vidas diárias contra a interrupção perturbadora dos tempos atuais. A capacidade de caminhar pelas paredes do xisto da vila e pelas florestas circundantes tornou-se um hábito diário comum (de manhã e à tarde, durante a semana e feriados). Desse modo, a prática espacial da caminhada surgiu como meio de passar o tempo, como prática estética, e como forma de autopromover saúde física e mental entre vizinhos e familiares. De igual modo, como o exemplo de Zé e Leonor nos mostram, praticar agricultura como modo de habitar o lugar tornou-se uma atividade central no cotidiano.

\section{"Testemunhos" como Aleph}

Viver na Mó significou construir identidades e relações sociais que extrapolam a dimensão do local e das relações sociais edificadas unicamente por esta via, recolocando o conceito de "não lugar" (AUGÉ, 1998), numa nova configuração empírica, já que permitiu vínculos efetivos para mais que a dimensão 
de passagem e transição, vínculos estes, muitos dos quais, construídos via novas tecnologias da informação.

Em todas as pequenas propriedades - chamadas terrenos - pertencentes a Mo, como em Sobreira Formosa e toda região de Proença Nova e parte de Castelo Branco, existe a prática de demarcar as propriedades com "testemunhos":

Ainda hoje em Proença há o costume visigótico de marcar os limites das propriedades com pedras (marcos) com vários sinais a que se juntam duas pedras mais pequenas a que chamam testemunhas (CATHARINO, 1933: 131).

Segundo Catharino (1933) é de uso corrente nesta região de Portugal a prática visigótica de demarcar e limitar o direito de propriedade, e de uso da terra. Para estabelecer limites de propriedade a que se unem marcos - pedras - que são ligadas umas as outras numa linha imaginária, que formam figuras geométricas que desenham o território. Cada um destes marcos é acompanhado de duas pedras menores fincadas uma ao lado da outra, a que chamam testemunhas, ou nesta zona no masculino: "testemunhos". Os testemunhos representam que cada um dos proprietários daqueles terrenos contiguos, estiveram reunidos ali (ou no mínimo aceitaram) aquela demarcação divisória, que foi "testemunhada", por uma pessoa da aldeia, normalmente a mais velha, ou de idoneidade ilibada e pública.

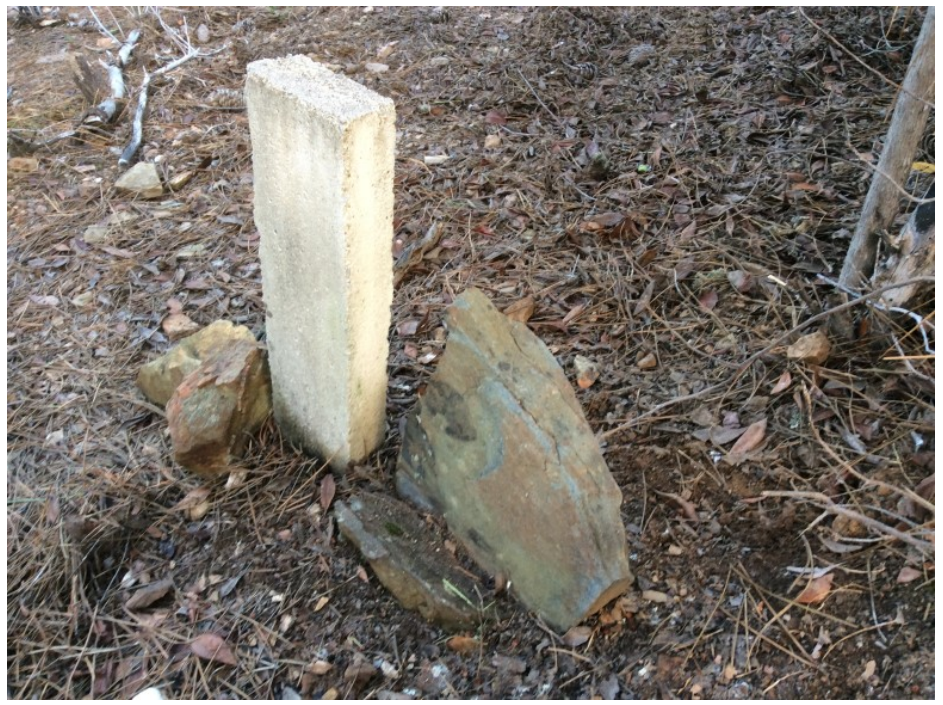

Figura 4: Marco e testemunhos, em uma das propriedades no pinhal: ao centro, o marco, de cimento, foi recolocado no local pelos proprietários, após os incêndios de 2003 (os anteriores marcos eram em xisto e foram destruídos pelo fogo). Este marco é ladeado por testemunhos, pedras em xisto. Autor: Ricardo Campos (2017). 
Destacamos estes marcos e testemunhos, em suas intercorrências como objeto e instituição, como uma espécie de signo, daqueles que gostamos de conhecer na perspectiva que estes nos unam a uma espécie de "elo perdido" que conecta o tempo em suas três conjugações, porém no sentido: presente, passado e futuro.

O Aleph é a letra inicial do alfabéto hebraico. Cheia de significados, possibilidades e desdobramentos nos alfabetos gregos e romano, assim, sugerindo um símbolo carregado de significados. O escritor argentino Jorge Luis Borges, publicou em 1949 uma das suas obras mais conhecidas, a qual deu o nome de Aleph. Neste livro de contos, Borges aborda temas como a imortalidade, a soberba, a identidade, a condição humana, o tempo, o duplo, a eternidade ${ }^{5}$. Quanto ao conto Aleph, que compõe o último da coletania, e que emblematiza (e não sintetiza, pois este termo parece não apropriado para o autor em questão), o significado do Aleph. Neste, o protagonista vê-se diante da possibilidade de conhecer o ponto central do espaço (mundo), que abarca toda a realidade do universo num único e inusitado local: o porão de uma casa antiga prestes a ser demolida que fica no centro de Buenos Aires.

Estes "testemunhos", presentes nos terrenos destas aldeias da Beira Baixa, figuram para nós como um signo, um emblema, o qual acreditamos pode ser a chave de leitura que reconecta o tempo destas aldeias, e da Mó em particular. Também como no conto Aleph, nos remete a emergência de um mundo (prática) a ser destruído. A idéia de "fragmento central" possibilita reconstruir a partir dos testemunhos "o tempo da aldeia".

\section{Para algumas (in)conclusões, a seu tempo}

O tempo regula a vida em sociedade, desde a revolução industrial, quando tempo e espaço (o trabalho cronometrado no chão da fábrica) são fatores que intensificam a civilização capitalista ou a sociedade de mercado. O tempo para Norbert Elias (1989) era a capacidade de sincronizar e uniformizar, uma convenção

5 - O Aleph é composto pelos contos: O imortal, O morto, Os teólogos, História do guerreiro e da cativa, Biografia de Tadeo Isidoro Cruz (1829-1874), Emma Zunz, A casa de Astérion, A outra morte, Deutsches Requiem, A busca de Averróis, O Zahir, A escrita de Deus, Abenjacan, o Bokari, morto no seu labirinto, Os dois reis e os dois labirintos, A espera, O homem no umbral, O Aleph. 
social, um símbolo que sintetiza e padroniza o comportamento social. Para este autor, a reiteração no tempo solidifica a mudança e padroniza os costumes, ou, então, "o tempo é o cimento que veda". Partindo da etnografia realizada, argumentamos que viver um tempo na Mó é uma experiencia de "viver um tempo fora do tempo", um tempo não padronizado, no qual o ritmo das relações sociais é outro; ainda que o autor pense o tempo como processo civilizatório, sugerimos pensar uma "nova civilização". Implica considerar que existe "um tempo", o tempo da civilização que introjetou seus recalques, permitindo a padronização de comportamentos. Ocorre que a natureza tem valvulas de escape e subterfugio, ainda que o ritmo das relações sociais seja ditado por necessidades ligadas ao elemento novo e inusitado da pandemia. Permanecendo o calendário como metrica do tempo, ou da sucessão de fatos que não se repetem, portanto, a inquietação que trazemos é: de que maneira a vivencia da pandemia que manteve as pessoas em isolamentos diferentes pelos quatro cantos do mundo, entrará na genealogia do tempo? Se a pandemia é a métrica, a diversidade de experiências de isolamento se cristalizará numa sintese civilizatória, que ao que tudo indica é diferente daquela radicalizada pela sociedade industrial, pelo frenesi dos centros urbanos e da sociedade de mercado.

\section{Referências Bibliográficas}

AUGÉ, M. Não lugares: introdução a uma antropologia da modernidade. Lisboa: Bertand, 1992.

BORGES, J. L. O Aleph. São Paulo: Companhia das Letras, 2008.

BORGES, J. L. Cinco Visões Pessoais. Brasília: UNB, 1985.

CATHARINO, Pe. M. A. Concelho de Proença-a-Nova (Monografia)Virtudes dos seus maioires e pléiade que vela o seu nobre passado, Lisboa: Companhia Editora do Minho/Barcelos, 1933.

ELIAS, N. .Sobre el tiempo. México: Fondo de Cultura Econômica.1989.

ELIAS, N. O processo civilizador - formação do estado e civilização. Rio de Janeiro: Jorge Zahar, 1993.

DIAS, J. Rio de Onor, Comunitarismo Agro-Pastoril. Porto: Instituto de Alta Cultura, Centro de Estudos de Etnologia Peninsular, 1953. 
HARVEY, D.Justice, Nature and the Geography of Difference. London: WileyBlackwell, 1996.

self and the social.

O'NEILL, B. Proprietários, Lavradores e Jornaleiras. Desigualdade Social numa Aldeia Transmontana, 1870-1978. Lisboa: Dom Quixote, 1984.

PIRES, E. e Campos, R. Mó "Mó: por uma (micro) política pública de paisagem?" Retirado de: https://www.publico.pt/2019/05/06/sociedade/opiniao/mo-micropoliticapublica-paisagem-1871422, 2019, 06 de maio.

PIRES, E. "Um lugar na floresta (I)" post in Confinaria - Blog,

available Retirado de: https://confinaria.hypotheses.org/840, 2020, 29 de abril.

PORTELA, José. Trabalho cooperativo em duas aldeias de Trás-os-Montes. Porto: Afrontamento, 1986.

RADIO CONDESTÁVEL : Proença-a-Nova - Aldeia da Mó continua processo de reconversão de áreas florestais, Cernache do Bonjardim - Sertã, Retirado de: https://www.radiocondestavel.pt/radio/index.php/noticias/32015-proenca-a-novaaldeia-da-mo-continua-processo-de-reconversao-de-areas-florestais, 2020, 06 de $\underline{\text { março. }}$

REED-DANAHAY, D. AUTO/ETHNOGRAPHY: REWRITING THE SELF AND THE SOCIAL.OXFORD: BERG, 1997.

REGIÃO - Castelo Branco: Proença-a-Nova : Plantação de árvores em Mó afirmam processo de reconversão de áreas florestais em agrícolas. Retirado de: https://www.diariodigitalcastelobranco.pt/noticia/52506/proenca-a-nova-plantacaodeve-arvores-em-mo-afirmam-processo-de-reconversao-de-areas-florestais-emagricolas, 2020, 09 de marco.

RTP 1 NOTÍCIAS: Aldeia de Proença-a-Nova reconverte áreas florestais em agrícolas. Retirado de: https://www.rtp.pt/noticias/economia/aldeia-de-proenca-anova-reconverte-areas-florestais-em-agricolas n1169378, 2019, 29 de agosto.

S.A. Lagares do Concelho de Proença-a-Nova, Proença-a-Nova: Câmara Municipal de Proença-a-Nova, 1982.

Vilhena, M. A. "Comunitarismo", Gentes da Beira Baixa. Aspectos Etnográficos do Concelho de Proença-a-Nova, Lisboa: Colibri, col. Sociedade e Quotidiano, pp. 5260, 1995. 